\title{
Compensatory Control Theory and Public Opinion on Nuclear Policy: Developing an Experimental Measure in an Applied Environmental Context
}

\section{OPEN ACCESS}

Edited by:

Tracylee Clarke,

California State University, Channel Islands, United States

Reviewed by:

Danielle E. Endres,

The University of Utah, United States

Jens Wolling,

Technische Universität IImenau,

Germany

*Correspondence:

Justin Reedy

jreedy@ou.edu

Specialty section:

This article was submitted to Science and Environmental

Communication,

a section of the journal

Frontiers in Communication

Received: 11 December 2018 Accepted: 04 June 2019

Published: 21 June 2019

Citation:

Anderson C and Reedy J (2019) Compensatory Control Theory and Public Opinion on Nuclear Policy: Developing an Experimental Measure in an Applied Environmental Context.

Front. Commun. 4:27.

doi: 10.3389/fcomm.2019.00027

\section{Chris Anderson and Justin Reedy* \\ Department of Communication and Center for Risk \& Crisis Management, University of Oklahoma, Norman, OK, United States}

In this study, we develop a novel measure of compensatory control to better understand how Compensatory Control Theory (CCT) impacts perceptions of government involvement in an environmental issue: the storage of spent nuclear fuel. Using a national survey, this study examines public opinion on nuclear waste storage, its risks, and potential forms of oversight, by creating four proxy measures of compensatory control. Those measures are used in a regression analysis to understand levels of participation and intervention in the siting of nuclear waste storage facilities. Results indicate mixed support for the measures and a clear connection to policy choices.

Keywords: nuclear policy, compensatory control, environment, deliberation, public opinion

\section{INTRODUCTION}

Public policy decisions in highly technical and esoteric domains, such as energy policy, offer a challenge from a public opinion perspective. Individual citizens may be less informed about these issues than other key stakeholders and decision makers. As a result, citizens may be excluded from or marginalized during a mostly technocratic policy making process (Fiorino, 1990; Kinsella, 2004; Kelshaw and Gastil, 2007). A notable exception to this participation problem is with some environmental issues, which can help mobilize large groups of citizens within the public sphere and may galvanize support or opposition to policy choices over time (Fiorino, 1990; Nisbet and Myers, 2007; Jenkins-Smith et al., 2011). However, environmental issues sometimes involve highly technical and esoteric subjects that are politically divisive but challenging for citizens to understand. The issue of nuclear power-and the attending topic of nuclear waste storage-is both a technical domain that is typically low on the public agenda but also an environmental domain that has seen occasional public scrutiny and generated deep opposition among committed stakeholders (Taylor et al., 2007; Jenkins-Smith et al., 2011). As the US continues to grapple with the problem of longterm storage of spent nuclear fuel and nuclear waste, as well as how to involve citizens in solving this problem (Blue Ribbon Commission, 2012; Trousset et al., 2015), questions remain about the factors that affect public views of nuclear power and waste storage. In this article, we set out to learn how perceptions of individual control apply in the public policy context of nuclear power and waste storage using a national survey on energy and environmental issues in the US. Our research suggests that Compensatory Control Theory (CCT), a theory from social psychology focused on individual need for control over external events (Kay et al., 2009), can help us better understand the basis for attitudes on control for environmental policy options and support for different processes of citizen-centered decision making on those policy choices. 
Feelings about nuclear energy have waxed and waned over the years as security risks, energy costs, and other factors have altered perceptions and attitudes about nuclear energy (Deutch et al., 2009). Some events decreased support for nuclear energy, such as the debate over Yucca Mountain and its use as a long-term nuclear storage waste facility. Negative attention on the site caused defunding of the project in 2010 (Rechard et al., 2014). Compounding that lack of support for nuclear energy was the Fukushima Daiichi nuclear disaster in 2011, when an offshore earthquake triggered a tsunami and caused damage to a nuclear reactor resulting in a meltdown of three of the reactors on site (Bird et al., 2014). The potential for disaster created trepidation and halted the trend of support for nuclear energy prior to these events. In the aftermath of these developments, the Blue Ribbon Commission on America's Nuclear Future argued for greater citizen involvement in siting nuclear waste facilities (Blue Ribbon Commission, 2012). However, government support for citizen involvement in siting seems to have declined under the Trump administration, as evidenced by a Department of Energy website about consent-based siting of facilities being taken down (Department of Energy, 2019). The administration has also proposed restarting the Yucca Mountain project in recent budget proposals (Associated Press, 2019).

Much of the research surrounding public opinion on nuclear energy and waste has focused on risk perceptions (Fahlquist and Roeser, 2014). Though public opinion on policy is certainly shaped by perceptions of risk, there are other factors that impact a person's opinion on a policy topic-for example, efficacy, credibility, and previous exposure to the issue. We set out to extend the study of public opinion on nuclear issues to include control through the lens of CCT, with two aims: First, we set out to test possible proxy measures for the components of internal and external control that characterize CCT, which is typically measured in an experimental context (Kay et al., 2008, 2010; Shepherd et al., 2011). Second, we use these proxy measures in an applied policy setting to try to understand the ways that CCT might predict an individual's support of policy-making processes about nuclear waste storage led by experts and citizens. We use a large national data set from 2014 that focuses on nuclear energy use and storage that is described in greater detail in the methods section below. Using an existing large data set allows for the use of a large number of participants but forces the use of proxy measures to understand internal and external control. Given the exploratory nature of this measure using a proxy to help identify key components seems fruitful.

Questions about policy making procedure and outcomes are influenced on varying levels by public support. Some research indicates that technical topics are often overlooked by citizen involvement. However, environmental decision making is often much more closely examined by citizens and generates much more citizen involvement (Dryzek and Pickering, 2017). Examining an issue like nuclear waste storage offers a great opportunity to see a combination of these two issues, given the technical and environmental nature of the topics of nuclear energy and waste storage. An individual's propensity to get involved in the policy process is important to develop public support and legitimacy (Cohen, 1997) and to find better solutions (Gastil, 2000). In addition, the deliberative turn in public engagement in recent years has resulted in the more widespread use of citizen-oriented policy processes in a range of contexts and on many different issues (Leighninger, 2012), particularly those involving environmental problems and issues of land use (Einsiedel and Eastlick, 2000; Daniels and Walker, 2001; Sprain and Reinig, 2018). Though scholars have noted the many deliberative deficiencies of public engagement processes on nuclear issues (Hamilton, 2007; Endres, 2009a,b; Kinsella et al., 2015), relatively few robust deliberative processes have been established to involve citizens in decision-making on nuclear waste management (Hamilton, 2004; Maxwell et al., 2004; Carson, 2017). As a result, there is still much to learn about public support for using deliberative forums in this area, which seems to have some public support (Trousset et al., 2015).

This study uses several items from across a survey to establish proxy measures of compensatory control. Typical applications of compensatory control have focused on experimental studies with message variables that create changes in beliefs about personal (internal) and global (external) levels of control (Kay et al., 2008). This study reverses the process by compiling items that serve as proxies for control as a first step to establishing more comprehensive measures. Our analysis shows that these measures are associated with the amount of oversight preferred by individuals and the likelihood of their active participation with the policy process related to nuclear storage facilities. In addition, the measures are related to a person's overall support for citizen deliberative forums.

\section{LITERATURE REVIEW}

\section{Compensatory Control Theory}

It is not surprising that people prefer a sense of order of the world around them with predictable relationships. This is not only the practical necessity of everyday cause and effect but also making sense of larger more ambiguous events. However, individuals may differ in their perceived need for order in their world. System justification theory describes an individual's need to feel order and predictability to have a sense of control, even at a cost, without which they slip into negative emotional states (Kay et al., 2008). Cases of racism, abusive relationships, and other oppressive hierarchies have been explained as a need to maintain a predictable order to the world (Laurin et al., 2008). Under the umbrella of system justification theory is Compensatory Control Theory, which identifies the cognitive process in which people use either individual action to control chaos or surrender to a higher controlling entity. The theory has often been examined in experimental settings where belief in a particular entity has been temporarily diminished (i.e., manipulated) to create changes in individual action or higher entity action. For example, participants are sometimes asked to remember a time in their life where events unfolded, and they had no control over the outcome (e.g., car accidents and weather events). The event recall can lead to a temporary decrease in individual-level control but participants may compensate with an increase in global control 
even on new unrelated tasks. There has been little work to identify if individuals might have a stable level of individual or entity control since it is typically only examined under manipulation.

The nuances of CCT help explain the ways in which individuals might have a more stable perception of the world than the threats provided in other research. While potentially susceptible to threats, individuals might have more stable conceptions that relate to perceptions of hierarchy or other world views. One of the first experiments involving CCT used an individual's reliance on a controlling god to provide order in situations where their perceptions of personal control had been decreased (Laurin et al., 2008). Perceptions of personal control were manipulated using messages that emphasized personal action, such as being able to call 9-1-1, or diminished, such as the police randomly arriving to help with the threat. Laurin et al. (2008) found support for the idea, "that when personal control was threatened during an anxiety-provoking visualization procedure, increased levels of self-reported anxiety were associated with increased subsequent beliefs in the likelihood of the existence of a controlling God" (p. 1561). Under threat, people feel a need to make sense of the world. When an individual perceives low levels of personal control, the individual is motivated to create a sense of order and often establishes support in larger external structures such as a controlling god.

People also rely on other external structures to provide feelings of order. For instance, researchers examined perceptions of climate change and an individual's motivation to find personal or external control through four different experiments (Shepherd et al., 2011). Their first experiment revealed that news articles that question scientific progress created anxiety compared with articles that affirmed scientific progress-in this case, technology and the scientific community served as an external force that provides external control and understanding of the world. Two other experiments showed that environmentally friendly behaviors such as recycling can be used to establish personal control and provide feelings of order. In their last experiment in the study, they found that when individuals receive messages that support scientific and technological progress, they are less likely to engage in environmentally friendly behaviors, which are a form of personal control. In addition, the converse is also supported: messages that indicate slow scientific progress increase participants' behavioral intention of recycling. This study reveals both that alternate external forces are used by individuals and that there is an inverse relationship between personal and external control.

The use of the government as a form of external control also comes with some interesting intersections with this current research. Often government is seen as an external force with little direct interaction from individuals to make changes in government (Kay et al., 2010). Participatory decision-making bodies-such as juries, deliberative panels, public comment periods, or any other type of individual opportunity to take part in governmental decisions-are examples of citizendriven government, giving someone the opportunity to directly influence government. The survey being used in this study asked participants their support for different kinds of government or industry oversight providing an opportunity for both a view as an external power as well as some level of personal control. This type of deliberative civic engagement has become more and more common in policy making (Delli Carpini et al., 2004; Leighninger, 2012), and a notable citizen engagement process on nuclear waste management seemed to succeed in part by giving citizens a measure of control in the outcome (Hamilton, 2004). As such, it bears asking how people with varying levels of internal and external control view such decision-making processes.

Scholarship in CCT has noted that threats to personal control can contribute to attitudes like a decreased resistance to government change, increased support for citizen-driven decision making, and increased faith in a government's ability to resolve an issue (Kay et al., 2008; Sullivan et al., 2010). Some work also supports the idea that perceptions of decreased personal control increases support for government control (Kay et al., 2008). Threats to personal control lead to increased faith in the governmental system, unless the political system is portrayed as unstable and unable to effectively ensure order (Sullivan et al., 2010). Government can be used as an external power but only when it is deemed competent to resolve issues. All of this work has conceptualized the government as an entity outside of personal influence and decision making, a place where a higher power makes a decision without the individuals being forced into making any choices or actions on their own.

\section{Public Deliberation on Policy Issues}

If traditional government processes are typically seen as external to individual citizens, deliberation presents government decision-making processes as a person's opportunity to interact directly with government and help influence public policy more directly. Deliberative public engagement is a process by which people spend time analyzing and discussing a public issue and reaching some kind of decision (Burkhalter et al., 2002). The most common form of deliberation in most democratic nations is the jury in a criminal or civil case (Hickerson and Gastil, 2008), but the deliberative democracy movement in recent decades has led to the rise of deliberative formats being used for public decisions in many contexts and levels of government (Nabatchi et al., 2012).

It takes careful planning and successful moderation in order to ensure that effective deliberation takes place. Several criteria have been used in order to ensure that a deliberative process is actually deliberation (Knobloch et al., 2013). Like any group of individuals, small changes to important aspects of the group can have a huge impact on the functioning of the group. Participation in the group is a key element, making deliberation an individual act of control over the environment instead of an external control. Rather than leaving the group to make decisions, any given person must engage themselves to make change.

There has been an increase in calls for citizen participation mostly seen through a myriad of grass roots movements such as the Tea Party, recent debates about compulsory voting, and campaigns having increased participation (Agarwal et al., 2014). Though government is often seen as an external source of control, it is possible to conceive of government as a sum of the citizens it is meant to represent. Deliberation has been only one tool that been used in order to increase citizen participation in 
government (Gastil et al., 2014). The opportunity for individuals to be able to participate in a deliberative event also has some long-term outcomes that include increased participation (Gastil et al., 2014). For the purpose of this study, deliberation and those individuals who support it may be a reflection of their outlook on government and their willingness and ability to make a governmental decision.

There is some work that describes the mindset required for deliberation to be successful. In many cases, deliberative processes begin with an orientation to this kind of forum and an explanation of the process as being open to multiple perspectives (Knobloch et al., 2013). Participants also have been known to refer to themselves as a collective and representation of the area they are helping make a decision for Fishkin et al. (2000). Being part of a deliberative panel changes the mindset of individuals involved, though support for deliberative processes have been mixed (Mutz, 2006). Perception of deliberation is complicated: some favor its use, but others do not. Perhaps understanding more about the people involved can impact how a person views the process of deliberation.

Policy making in the domain of nuclear power and waste storage has tended toward technical and expert decisions, sometimes leading to strong public backlash (Blue Ribbon Commission, 2012) and the marginalization of affected communities like Native American tribes (Endres, 2009b, 2012). Nuclear communication scholarship has examined the many deliberative shortcomings of decision-making processes on nuclear facility siting, which often feature limited opportunities for public involvement and deep divisions between citizens and policymakers (Hamilton, 2007; Kinsella et al., 2015). Deliberative forms of engagement have increasingly been applied in the area of nuclear waste and facility siting in recent years in the US and other nations (Hamilton, 2004; Maxwell et al., 2004; Carson, 2017). Citizens in areas affected by nuclear waste seem to want robust opportunities to participate in policy making, despite the limitations in their actual opportunities to participate and a perception among some elites that they may be unqualified to do so (Hamilton, 2004; Kinsella et al., 2015). Citizen backlash and activism against less responsive processes have helped force greater government transparency and stronger inclusion in nuclear policy (Hamilton, 2007). Scholars have also noted the potential for citizens to meaningfully participate in deliberative nuclear policy governance through purposeful use of experts and thoughtful process design (Kinsella, 2004; Endres, 2009a). In addition, US government experts have expressed support for having communities consent to waste facility siting through a process of public engagement (Blue Ribbon Commission, 2012), though government interest in such approaches seems to have waned since the change in the presidential administration (see e.g., Department of Energy, 2019, as noted above). Though research on public engagement on nuclear storage has shown broad support for citizen involvement in decision making (Trousset et al., 2015), there is much more to learn about the nature of that support.

\section{Hypotheses}

Compensatory control theory is often explained as an inverse relationship between internal control through personal action and external control through some other power. External powers that have been examined include religion, government, or superstition. These external forces can be exchanged between one another: In one situation a religious icon may be handling your exam grade but on the basketball court a four-leaf clover may manage your skills. If the issue is not being managed externally, a person may engage in certain behaviors in order to establish a sense of control. Often superstitious behaviors are explained as a way in which an individual is taking some personal control over the world when external forces have failed. Most research examining manipulations has taken place with experimental manipulations but by creating a proxy measure for personal control using existing data it seems possible to test a new range of questions. Of particular interest is how levels of personal control might impact a person's trust and willingness to engage in deliberation or other communication processes. Part of that willingness is based in a fundamental trust of the mechanisms of action to accomplish something.

According to Kay et al. (2008), individuals who are low in personal control put extensive power into external sources. The inverse relationship between personal and external control is used by individuals to give order to the world. As such, individuals who perceive having low levels of personal control will surrender personal agency to a larger external power, and often defend this particular world view. In the case of giving control to larger governmental bodies, individuals will defend the fact that government is an effective decision-making organization. As such we hypothesize that:

H1: Individuals with higher levels of perceived external control will be less likely to want to participate in a governmental decision on nuclear waste facility siting.

When individuals feel that they have to take control of their own lives rather than waiting for the government to make a decision they are more likely to want to be involved in that process in order to exert that personal control over the decision. When large governmental bodies make decisions, people are placing the level of control in an external force, but CCT explains that in the inverse people will want to engage in behaviors in order to control those outcomes themselves and give them a sense of personal control. A deliberative forum is only one example of how individuals would want to be in control of a decisionmaking process.

H2: Individuals with higher levels of perceived external control will be more likely to support expert decision-making panels over citizen decision-making panels on nuclear waste facility siting.

Other research has supported the notion that individuals must justify their use of one form or control over another in order for it to be most effective (Kay et al., 2009; Rutjens et al., 2010). That justification often manifests as faith that god exists, or that government is effective. If individuals do not think that government is effective then they have less support for its outcomes. Other studies have used measures of government benevolence that solely measured corruption and have found strong results across several countries (Kay et al., 2008). Low personal control only correlates with government external 
control (instead of religious control, or some other external control) when there is faith that the government is capable of making outcomes possible for the individual. We would expect that individuals with high levels of perceived personal control will be motivated to act on that personal agency and thus be more involved in the process of making decisions. One way in which to do this is to contact policy makers who have control over the decision-making process. The more individuals who have that power, the more personal control and contact a single individual could have on the decision-making process.

H3: Individuals with higher levels of perceived external control will be less likely to support more policy makers having veto power in the placement of interim nuclear waste storage facilities.

\section{METHODS}

The Energy and Environment Survey (EE) has been a longterm collaboration between the Center for Risk and Crisis Management and Center for Energy, Security, and Society at the University of Oklahoma and Sandia National Laboratories to track the attitudes and beliefs of American citizens about nuclear energy and nuclear waste storage. While the EE survey has been administered for many years, this study utilizes the data collected in 2014. The survey included several questions related to interim storage facilities, one proposed method for dealing with spent nuclear fuel until a long-term repository is devised and constructed (Blue Ribbon Commission, 2012).

Participants were recruited through a paid research service, Survey Sampling Inc., which has a database of more than six million research respondents plus millions of others through partnered firms across 54 countries. The EE survey was distributed in the US using quota sampling to carefully match the 2013 Census for age, gender, ethnicity, religion, and region to best represent the United States population as a whole. The survey was conducted in accordance with a protocol approved by the Institutional Review Board at the University of Oklahoma.

The EE survey was completed by 1,610 adults through online distribution over two days in late June 2014. Survey respondents had roughly equal gender distribution (45.4\% men and 54.6\% women). Generational age distribution matched closely to US demographics for people 18 and older, with those aged 18-29 making up $11.7 \%$ of the EE survey respondents $(21.8 \%$ U.S. Census), $30-49$ making up $29.5 \%$ (34.2\% U.S. Census), and 50 or older making up $58.9 \%$ (44.0\% U.S. Census). Ethnicity distribution of the survey also matched Census data within $1.5 \%$. Regions of the United States were divided into four areas: Northeast, Midwest, South, and West, with the survey matching the Census within $0.2 \%$. Overall the sample was balanced carefully to match the national census to offer a strong representation of the diversity of attitudes and beliefs in the United States.

\section{Measures}

Previous CCT research does not utilize manipulation checks and relies almost entirely on outcome measures with attitude or behavioral implications beyond the scope of the manipulation itself. For example, reading about the pace of technological development impacts intended recycling behavior (Meijers and Rutjens, 2014). This article is an attempt to use a large data set to reverse engineer some of the contours of control from CCT. This method makes use of a large diverse data set to gain strong statistical power from an adult population and can only provide a partial understanding of compensatory control. Qiu et al. (2018) note that questions of validity are a problem when using large second-hand data. These issues can be caused by increased error in collection, over confidence in automated tools, and reliance on unsupported proxy measures. The primary concern in this study is the use of proxy measures as we feel the error is limited in this professionally collected sample and we use no automated analysis tools like computational sentiment analysis. Each of the CCT proxy measures found in our data set has grounding in previous work from other researchers using CCT, lending validity to the measure, but given that the analysis uses second-hand data it is not perfectly capturing the construct.

\section{Dependent Measures}

This study utilizes three dependent measures based on behavioral opportunities to increase participation in a consent-based siting process. Behavioral based measures, particularly within government perception domains, have been used in CCT research before (see Kay et al., 2008, 2010; Mirisola et al., 2014). The first measure focuses on direct political participation, and is an average of six questions on a person's selfreported likelihood to engage in different types of public support, opposition, and decision-making for nuclear waste storage facilities. These questions were all behavioral items based on standard measures of political participation but altered for this context; they included attending informational meetings, speaking at meetings, using social media, writing to key stakeholders, and participating in a forum on the issue (Cronbach's alpha $=0.845$ ).

An additional measure of internal and external control was created from five items about a person's support for using citizenbased decision making versus expert-based decision making on a range of issues. The questions were averaged into a single scale (Cronbach's alpha $=0.723)$. Though this scale did not directly measure a person's likelihood to engage in the decision-making process, it provides a rough estimation of support for decision making at a level closer to themselves compared with more external technical experts. Participants who score low on the measure should be more in favor of the external control of an expert board over the internal control of a citizen-based panel in which they would be more likely to participate or be represented.

Our third and final dependent measure to assess control is an additive scale created from a series of 12 questions about what entities should be able to veto a project involving nuclear waste storage. These questions simply asked participants who should be able to veto the construction of a spent nuclear fuel interim storage facility in a community, with many options ranging from governmental offices and organizations to interested nongovernmental organizations. A sum of all the vetoes was used to capture the number or people or organizations an individual 
would want to have control over this issue (Range $=0-12, M$ $=5.56, S D=3.15)$. We assume that internal control would increase as the number of veto parties increase because of the corresponding increase in intervention points where influence might change the process. External control is represented at lower scores because of the trust given to external systems without intervention points for the individual.

\section{Independent Measures}

To create the proxy measure for CCT, every item that mentioned control or organizational support/opposition was included in a factor analysis. These items were scrutinized for underlying patterns via factor analytic procedures with an oblimin rotation. Items were removed from the analysis in an iterative process with the lowest loading item removed, the analysis recalculated, and the process repeated until all items loaded on to only a single factor with a loading above 35; see Table $\mathbf{1}$ for factor analysis factor loadings. After several rounds of removal, four factors with satisfactory loadings were identified and reliabilities were measured: trust (scale alpha $=0.931)$, risk $(0.929)$, environmental concern (0.824), and national stability (0.805). It is important to note all of these items involved governmental or nongovernmental organizations and their ability to handle a myriad of issues but focused heavily on the regulation of nuclear waste storage.
The first factor of trust has been examined as a component of a compensatory mechanism, specifically when examining institutions (Shockley and Shepherd, 2016). Personal control and institutional trust have an inverse relationship, we should expect that as trust increases individuals will be less interested in direct control over decisions. The second factor we have named risk. Risk references a person's willingness to tolerate the threat of a potential negative outcome. That threat serves to disrupt the order of a person's experience, an act requiring compensation from the larger umbrella of system justification theory and the specific action of managing control from CCT (Shepherd et al., 2011). As perceptions of risk increases a person would be expected to protect their status quo through direct personal action. The third factor titled national stability has been linked to compensatory behavior because of a connection to the stability and predictability of the world to the individual. Fluctuations in regular expenditures like healthcare or energy can disrupt the predictable patterns that individuals often rely on leading to compensatory reactions (Kay et al., 2009). Like risk, environmental concern and control have a positive relationship. The fourth factor of environmental concern focuses on generalized health of the Earth related to the environment. CCT has examined the relationship of control and the environment, finding that control can manipulate a person's willingness to engage in more environmentally

TABLE 1 | Compensatory control item wording and loadings.

\begin{tabular}{|c|c|}
\hline Factor 1 item wording & Loadings \\
\hline \multicolumn{2}{|l|}{ Indicate your level of trust in information provided by science and engineering experts from each of the following organizations } \\
\hline The U.S. Nuclear Regulatory Commission & 0.907 \\
\hline The U.S. Department of Energy & 0.887 \\
\hline U.S. national laboratories for energy and security & 0.858 \\
\hline State regulatory agencies & 0.841 \\
\hline The Nuclear Energy Institute, which represents the nuclear power industry & 0.794 \\
\hline The U.S. Environmental Protection Agency & 0.775 \\
\hline Utility companies that own nuclear power plants & 0.743 \\
\hline The National Academy of Sciences & 0.690 \\
\hline How much of the time do you trust the government in Washington to do what is right for the American people? & 0.407 \\
\hline \multicolumn{2}{|l|}{ Factor 2 item wording } \\
\hline \multicolumn{2}{|l|}{ Consider both the likelihood of a nuclear event occurring and its potential consequences when evaluating the risk posed by each of the following } \\
\hline An event at a U.S. nuclear power plant within the next 20 years that results in the release of large amounts of radioactivity & 0.923 \\
\hline An event during the transportation or storage of used nuclear fuel from nuclear power plants in the U.S. within the next 20 years & 0.908 \\
\hline A terrorist attack at a U.S. nuclear power plant within the next 20 years that results in the release of large amounts of radioactivity & 0.819 \\
\hline The diversion of nuclear fuel from a nuclear power plant in the U.S. within the next 20 years for the purpose of building a nuclear weapon & 0.814 \\
\hline \multicolumn{2}{|l|}{ Factor 3 item wording } \\
\hline \multicolumn{2}{|l|}{ How concerned are you about: } \\
\hline The availability and cost of energy in the U.S.? & 0.755 \\
\hline The state of the economy, including jobs and inflation? & 0.752 \\
\hline The delivery and cost of healthcare in the U.S.? & 0.684 \\
\hline Threats to national security, including terrorism? & 0.640 \\
\hline \multicolumn{2}{|l|}{ Factor 4 item wording } \\
\hline How much risk do you think global warming poses for people and the environment? & 0.796 \\
\hline How concerned are you about the effects of human activities on the environment? & 0.708 \\
\hline Where 0 means that nature is robust and not easily damaged and 10 means nature is fragile and easily damaged, how do you view nature? & 0.593 \\
\hline
\end{tabular}

All questions ranged in response from 0-10 and question instructions provided at each factor or within question text. 
conscious behaviors (Meijers and Rutjens, 2014). Given the compensatory nature of control, perceptions of these factors within the context of nuclear waste storage should have related outcomes.

\section{RESULTS}

Multiple regression analysis was used to test if the four Compensatory Control factors as well as demographic and political variables were significantly associated with the participation variable, which measured self-reported interest in engaging in various kinds of public participation related to nuclear waste facility siting. The results of the regression indicated the four factors plus race, gender and education explained $14.1 \%$ of the variance $\left[R^{2}=0.141\right.$, $\left.F_{(8,1384)}=29.556, p<0.001\right]$. This regression model appears in Table 2.

The regression analysis for participation in events related to the placement of a nuclear waste storage facility gives the strongest support for an application of control via CCT to this applied context. In $\mathrm{H} 1$, we hypothesized that people with higher levels of perceived external control will be less likely to want to participate in a governmental decision on nuclear waste facility siting. The factors for risk (two), and national stability (three), and environmental concern (four) are all positively associated with wanting to participate, which all provide support for H1. Factor one, trust in governmental and non-governmental organizations, is negatively associated with wanting to participate, which also supports $\mathrm{H} 1$ and control (though this relationship is the weakest of the four). These results are indicative that there is some evidence that these factors are proxy measures of control and decisions to participate.

Multiple regression analysis was also used to test the same predictors and support for citizen versus expert panels in addressing nuclear waste storage siting (higher scores in the dependent variable indicate support for citizen panels). Results identified that $9.3 \%$ of the variance was accounted for by the factors and demographics $\left[R^{2}=0.093, F_{(8,1382)}=18.792, p<\right.$ 0.001]. This regression model is presented in Table 3.

The second regression analysis provides mixed support for the hypothesized relationships between external control

TABLE 2 | Predictors of participation in nuclear waste facility siting.

\begin{tabular}{lccc}
\hline Variable & $\boldsymbol{B}(\mathrm{SE})$ & $\boldsymbol{\beta}$ & $\boldsymbol{p}$ \\
\hline Age & $-0.005(0.003)$ & -0.05 & 0.059 \\
Education & $0.208(0.031)$ & 0.168 & $<0.001$ \\
Gender & $0.317(0.085)$ & 0.097 & $<0.001$ \\
Percent white & $-0.266(0.106)$ & -0.065 & 0.013 \\
Factor 1 trust & $-0.091(0.043)$ & -0.054 & 0.034 \\
Factor 2 risk & $0.244(0.052)$ & 0.146 & $<0.001$ \\
Factor 3 national stability & $0.113(0.050)$ & 0.064 & 0.023 \\
Factor 4 environmental concern & $0.394(0.049)$ & 0.221 & $<0.001$ \\
\hline
\end{tabular}

$N=1,393, F=29.556 p<0.001, R^{2}=0.141$ and support for expert panels. According to CCT, we would expect individuals who are high in control (internal) would be much more likely to support expert panels. In this regression model, factors one (trust), two (risk), and four (environmental concern) are negatively associated with support for citizen panels. Factor three (national stability) is significantly associated with support for citizen panels, but the direction of the relationship is positive. Factors one and three behave as hypothesized but factors two and four are significant and in the wrong direction. Overall, we find partial support for $\mathrm{H} 2$.

A third multiple regression analysis was conducted to identify the factors associated with a desire for governmental oversight in the facility siting process, in this case quantified by the number of parties' respondents would want to have a veto over the placement of a storage facility. Results using the same independent and control variables as the above found that these variables account for $6.9 \%$ of the variance $\left[R^{2}=0.069, F_{(8,1384)}\right.$ $=13.973, p<0.001]$. This regression appears in Table 4 .

We hypothesized that individuals who had higher perceived external control through the proxy measures should favor giving fewer people or entities veto power over facility siting. More vetoes allow for more instances of intervention, which in turn allows for personal control and offers the possibility that personal control options might have more

TABLE 3 | Predictors of support for panel type (higher scores indicate support for citizen panels).

\begin{tabular}{lccc}
\hline Variable & $\boldsymbol{B}(\mathrm{SE})$ & $\boldsymbol{\beta}$ & $\boldsymbol{p}$ \\
\hline Age & $-0.003(0.001)$ & -0.057 & 0.036 \\
Education & $0.052(0.013)$ & 0.104 & $<0.001$ \\
Gender & $-0.047(0.035)$ & -0.035 & 0.188 \\
Percent white & $0.128(0.044)$ & 0.077 & 0.004 \\
Factor 1 trust & $-0.115(0.018)$ & -0.170 & $<0.001$ \\
Factor 2 risk & $-0.075(0.022)$ & -0.111 & 0.001 \\
Factor 3 national stability & $0.133(0.021)$ & 0.185 & $<0.001$ \\
Factor 4 environmental concern & $-0.067(0.021)$ & -0.093 & 0.001 \\
\hline
\end{tabular}

$N=1,391, F=18.792 p<0.001, R^{2}=0.093$

TABLE 4 | Predictors of number of entities with facility siting veto power.

\begin{tabular}{llrr}
\hline Variable & \multicolumn{1}{c}{$\boldsymbol{B}$ (SE) } & $\boldsymbol{\beta}$ & $\boldsymbol{p}$ \\
\hline Age & $0.014(0.006)$ & 0.061 & 0.027 \\
Education & $-0.085(0.068)$ & -0.033 & 0.213 \\
Gender & $-0.295(0.185)$ & -0.043 & 0.111 \\
Percent white & $0.580(0.233)$ & 0.067 & 0.013 \\
Factor 1 trust & $-0.054(0.094)$ & -0.015 & 0.564 \\
Factor 2 risk & $0.427(0.114)$ & 0.121 & $<0.001$ \\
Factor 3 national Stability & $0.607(0.109)$ & 0.163 & $<0.001$ \\
Factor 4 environmental concern & $0.124(0.108)$ & 0.033 & 0.251
\end{tabular}

$N=1,393, F=13.973 p<0.001, R^{2}=0.069$. 
impact. Factors two and four were significant along with age and race. Those variables had positive relationships which as the factors are concerned is in line with CCT and while the others were no were near significant they were in the expected direction/ Overall, we found weak support for $\mathrm{H} 3$.

\section{DISCUSSION}

Taken as a whole, the results offer some evidence that these factors are valid constructs for some of the core concepts from Compensatory Control Theory, and in turn help show how compensatory control might impact governmental decisionmaking processes on environmental issues. This bolsters the qualitative and rhetorical scholarship on nuclear communication that highlights the importance of individual control and influence on nuclear governance (Hamilton, 2004, 2007; Endres, 2009a). Of particular interest here is a person's likelihood to get involved in and support processes such as deliberation as a result of their belief in external or internal control. Our first regression provides the most robust results, likely because it has the most direct measure of individual control and has no mitigating outside structures like community panels or vetoes included in the other regression models. The combination of these models suggestive but not conclusive that these proxy measures impact control. Some of the conflicting findings, especially in models two and three, could be the result of indirect measurement of control in the dependent measures of the panel type and veto action. At the very least, these encourage further investigation of measuring control, which has been a key factor in other studies of nuclear governance (e.g., Hamilton, 2007).

The dependent measures have two purposes here. The measures are a connection to the behavioral outcomes common in CCT research and serve as a measurement for willingness to participate in deliberative processes related to consentbased siting. The first regression using dependent measures surrounding direct willingness to participate is the best connection to control and model one suggests that all four factors are important to the perception of control. Given the compensatory nature of control from theory, fluctuations in these factors seem related to individual perception of external or internal control. Direct control is an important aspect especially in the nuclear context because of the perception of bad faith efforts in previous attempts at public participation (Hamilton, 2007). This is the reason why understanding how control relates to public participation, especially within this context, is important. As the kind of process presented to respondents shifts, from more direct modes of participation to more indirect forms, the underlying reasons for supporting or engaging in that process can change dramatically. Our results suggest that the factors of control identified in the factor analysis are less likely to be influential as participation opportunities are farther removed from an individual.
Political participation has been studied from many perspectives with perhaps the most examination from efficacy scholars. There is strong evidence that efficacy is one of the most important factors in participation and that control as a construct shares some conceptual similarities with it. Though this study was not designed to split these two concepts, other research being developed suggests that these cover discrete domains even if they have some overlap (Anderson and Harrison, 2019). That research suggests that control manipulations, like those used in CCT, can be measured by control scales but not by common efficacy scales. The general distinction is that one can perceive being efficacious but perceive no control or perceive control but perceive no efficacy. For example, I may feel like I can vote but that my vote has no power or that I could perform well as national athlete but will never have an opportunity.

This study provides some preliminary insights into the complex relationship between a sense of control and political participation. The findings presented here offer some support for potentially boosting citizen participation through processes like public deliberation, even in quite esoteric domains like storage of spent nuclear fuel (Endres, 2009a). Deliberation as a tool for increased public participation has been steadily growing over the past 30 years (Leighninger, 2012), and there have been some efforts to include deliberative processes in nuclear governance (Maxwell et al., 2004; Carson, 2017). This study provides some understanding about kinds of issues that might benefit from citizen deliberation or the kinds of issues best suited for expert deliberation. Individual differences also might contribute to who would support these sorts of participation opportunities and those who would like to disengage from the political process.

Previous manipulations of control often take advantage of the extreme conditions of external or internal control. This helps maximize the impact of a sense of control in an experimental setting. But it seems far more likely that, without prompting, an individual is more likely to be somewhere in between one perspective or the other. These leanings are likely to play a partial role in behavioral actions like voting, advocating, or approaching change because when manipulated to their extremes they show impact in a broad range of behavioral outcomes (Shepherd et al., 2011). While the control outcomes are not as likely to be the main source of variation, it is important to understand what more standard perceptions of control may change in decision making and in perceptions of process.

It is also important to recognize some places in which these measures fall short. Examining the second regression model, there is a complicated relationship with risk and environmental concern. It is important to mention that one of the expert versus citizen panel questions specifically focused on climate change, which may have had some impact on the relationship between panel support and environmental concern. Given that education and age can be dividing lines in issue position around climate change, and were both significant in these models, it is possible that issue salience overrides other factors in this domain. This might highlight that some issues may be impervious to perceptions of control and that more purposeful measures need 
to be used. It is possible that individuals who care about the environment also realize the limitations of their own knowledge and wish to have experts with more technical knowledge address these issues. This also gives more support to ideas for utilizing experts more thoughtfully in deliberative processes to better support citizen discussion and deliberation (Kinsella, 2004; Endres, 2009a; Sprain et al., 2014).

The sum of the vetoes measure might also introduce limitations in the results; it would be hard for any person to believe in no governmental oversight in placing a nuclear storage facility. Because of this, there may have been a floor effect where the vetoes were impossible to bottom out on the scale. This seems possible, given that the trust factor was not significant in the model. There are some competing concerns that may make the trust scale problematic in a model about governmental vetoes. Their use requires trust in the agencies involved, but also not having them involved requires a trust that they serve their functions, like operations, correctly.

Though all three regression models were significant, and provided some support for our hypotheses, they also only explained a modest portion of the variance in the dependent variables. That is a limitation of our analysis, though it is to be expected given the exploratory nature of the study. Using proxy measures for the core concepts of CCT created a somewhat fuzzy picture of how CCT might apply in this domain, though there was some underlying support for using CCT in the area of energy and associated risks. Creating a more distilled form of the measure is an obvious next step. Utilizing more work in CCT and testing it in the more traditional ways it has been used before might offer some clear insights in how internal and external control impact public opinion related behaviors (Kay et al., 2008).

The ways in which environmental issues and individual control interact are not always as straightforward as control serving as environmental protection. Public perception of nuclear energy is nuanced: for some, nuclear energy is a solution to environmental degradation, whereas others see it as a form of degradation due to the creation of nuclear waste (Kinsella et al., 2015). Some proponents of community siting of nuclear waste storage have even used cultural arguments of responsible stewardship to encourage the adoption of the nuclear waste, which runs counter to the more common cultural narrative of environmental protectionism (Clarke, 2010). Nuclear issues function at the crossroads of environmentalism and energy production. This should force decision makers to grapple with the technical consequences of adoption, emotional appeals of risk, and the abstract cultural values necessary to reach consensus

\section{REFERENCES}

Agarwal, S. D., Barthel, M. L., Rost, C., Borning, A., Bennett, W. L., and Johnson, C. N. (2014). Grassroots organizing in the digital age: considering values and technology in tea party and occupy wall street. Inform. Commun. Soc. 17, 326-341. doi: 10.1080/1369118X.2013.873068

Anderson, C. E., and Harrison, J. (2019). "The role of individual control in perception of bureaucratic institutions," in Midwest Political Science Association Conference (Chicago, IL) for moving forward (Blue Ribbon Commission, 2012; Endres, 2012). Understanding how communities want control in both process and outcomes becomes necessary if policymakers hope to transcend the common outcome of a policy decision followed by a litigious response. This study begins to examine this complexity in a distinct way from previous research on nuclear public engagement.

This study shows that it is fruitful to examine and measure compensatory control elements as they relate to a myriad of issues. In doing so we gain valuable insight into the kinds of processes that might drive political participation in terms of the kinds of processes offered to individuals. While existing work has measured the outcomes of manipulating internal and external control, establishing a direct measure of individuals' sense of control can help in better understanding this concept as a stable trait as opposed to manipulated conditions. This study is a first step in clarifying how control factors into public participation and offers strong encouragement for further development.

\section{ETHICS STATEMENT}

This study was carried out in accordance with the recommendations of the University of Oklahoma Institutional Review Board with written informed consent from all subjects. All subjects gave written informed consent in accordance with the Declaration of Helsinki. The protocol was approved by the University of Oklahoma Institutional Review Board.

\section{AUTHOR CONTRIBUTIONS}

$\mathrm{CA}$ is responsible for the conception and design of this study, both CA and JR conducted the data analysis and wrote the manuscript. Both authors contributed to revision of the manuscript.

\section{FUNDING}

This project was not supported by any external funding sources.

\section{ACKNOWLEDGMENTS}

The authors would like to thank Hank Jenkins-Smith, Kuhika Gupta, Carol Silva, and Joseph Ripberger at the University of Oklahoma for their contributions in providing the survey data described herein, and to the University of Oklahoma Center for Risk \& Crisis Management and Center for Energy, Security, \& Society for supporting the survey.

Associated Press (2019). Perry Defends Plan for Nevada nuclearWaste Storage Site. Retrieved from: https://www.apnews.com/ 7702c190230e42c295807817537311e8 (accessed March 29, 2019)

Bird, D. K., Haynes, K., van den Honert, R., McAneney, J., and Poortinga, W. (2014). Nuclear power in Australia: a comparative analysis of public opinion regarding climate change and the Fukushima disaster. Energy Policy 65, 644-653. doi: 10.1016/j.enpol.2013.09.047

Blue Ribbon Commission (2012). Report to the Secretary of Energy. Washington, DC: Blue Ribbon Commission on America's Nuclear Future. Available online 
at: http://energy.gov/sites/prod/files/2013/04/f0/brc_finalreport_jan2012.pdf (accessed August 1, 2018).

Burkhalter, S., Gastil, J., and Kelshaw, T. (2002). A conceptual definition and theoretical model of public deliberation in small face-to-face groups. Commun. Theory 12, 398-422. doi: 10.1111/j.1468-2885.2002.tb 00276.x

Carson, L. (2017). Learnings from South Australia's Nuclear Fuel Cycle Jury. The newDemocracy Foundation. Retrieved from: https://www.newdemocracy.com. $\mathrm{au} /$ research/research-notes/432-learnings-nuclear-jury

Clarke, T. (2010). Goshute native american tribe and nuclear waste: complexities and contradictions of a bounded-constitutive relationship. Environ. Commun. 4, 387-405. doi: 10.1080/17524032.2010.520724

Cohen, J. (1997). "Deliberation and democratic legitimacy," in Deliberative Democracy: Essays on Reason and Politics, eds J. Bohman and W. Rehg (Cambridge, MA: MIT Press), 67-91.

Daniels, S. E., and Walker, G. B. (2001). Working Through Environmental Conflict: The Collaborative Learning Approach. Westport, CT: Praeger.

Delli Carpini, M. X., Cook, F. L., and Jacobs, L. R. (2004). Public deliberation, discursive participation, and citizen engagement: a review of the empirical literature. Ann. Rev. Polit. Sci. 7, 315-344. doi: 10.1146/annurev.polisci.7.121003.091630

Department of Energy (2019). Consent Based Siting. Retrieved From: https://www. energy.gov/ne/initiatives/consent-based-siting (accessed February 28, 2019)

Deutch, J., Moniz, E., Ansolabehere, S., Driscoll, M., Gray, P., Holdren, J., et al. (2009). The Future of Nuclear Power: Update to the 2003 Report. Retrieved from the MIT Energy Initiative: https://web.mit.edu/nuclearpower/

Dryzek, J. S., and Pickering, J. (2017). Deliberation as a catalyst for reflexive environmental governance. Ecol. Econo. 131, 353-360. doi: 10.1016/j.ecolecon.2016.09.011

Einsiedel, E. F., and Eastlick, D. L. (2000). Consensus conferences as deliberative democracy: a communications perspective. Sci. Commun. 21, 323-343. doi: $10.1177 / 1075547000021004001$

Endres, D. (2009a). Science and public participation: an analysis of public scientific argument in the yucca mountain controversy. Environ. Commun. 3, 49-75. doi: $10.1080 / 17524030802704369$

Endres, D. (2009b). The rhetoric of nuclear colonialism: rhetorical exclusion of american indian arguments in the yucca mountain nuclear waste siting decision. Commun. Critical/Cult. Stud. 6, 39-60. doi: $10.1080 / 14791420802632103$

Endres, D. (2012). Sacred land or national sacrifice zone: the role of values in the yucca mountain participation process. Environ. Commun. 6, 328-345. doi: $10.1080 / 17524032.2012 .688060$

Fahlquist, J. N., and Roeser, S. (2014). Nuclear energy, responsible risk communication and moral emotions: a three level framework. J. Risk Res. 18, 1-14. doi: 10.1080/13669877.2014.940594

Fiorino, D. J. (1990). Citizen participation and environmental risk: a survey of institutional mechanisms. Sci. Technol. Human Valu. 15, 226-243. doi: $10.1177 / 016224399001500204$

Fishkin, J. S., Luskin, R. C., and Jowell, R. (2000). Deliberative polling and public consultation. Parliament. Affairs 53, 657-666. doi: 10.1093/pa/53.4.657

Gastil, J. (2000). Is face-to-face citizen deliberation a luxury or a necessity? Polit. Commun. 17, 357-361. doi: 10.1080/105846000501 78960

Gastil, J., Richards, R. C., and Knobloch, K. R. (2014). Vicarious deliberation: how the oregon citizens' initiative review influenced deliberation in mass elections. Int. J. Commun. 8, 62-89. Available online at: https://ijoc.org/index.php/ijoc/ article/view/2235/1049

Hamilton, J. D. (2004). "Competing and converging values of public participation: A case study of participant views in Department of Energy nuclear weapons cleanup," in Communication and Public Participation in Environmental Decision Making, eds S. P. Depoe, J. W. Delicath, and M.-F. A. Elsenbeer (Albany, NY: SUNY Press), 58-81.

Hamilton, J. D. (2007). "Convergence and divergence in the public dialogue on nuclear weapons cleanup," in Nuclear Legacies: Communication, Controversy, and the U.S. Nuclear Weapons Complex, eds B. C. Taylor, W. J. Kinsella, S. P. Depoe, and M. S. Metzler (Lanham, MD: Lexington Books), 41-72.
Hickerson, A., and Gastil, J. (2008). Assessing the difference critique of deliberation: gender, emotion, and the jury experience. Commun. Theory 18, 281-303. doi: 10.1111/j.1468-2885.2008.00323.x

Jenkins-Smith, H. C., Silva, C. L., Nowlin, M. C., and deLozier, G. (2011). Reversing nuclear opposition: evolving public acceptance of a permanent nuclear waste disposal facility. Risk Anal. 31, 629-644. doi: 10.1111/j.1539-6924.2010.01543.x

Kay, A. C., Gaucher, D., Napier, J. L., Callan, M. J., and Laurin, K. (2008). God and the government: testing a compensatory control mechanism for the support of external systems. J. Personal. Social Psychol. 95:18. doi: 10.1037/0022-3514.95.1.18

Kay, A. C., Shepherd, S., Blatz, C. W., Chua, S. N., and Galinsky, A. D. (2010). For God (or) country: the hydraulic relation between government instability and belief in religious sources of control. J. Personal. Soc. Psychol. 99:725. doi: $10.1037 / \mathrm{a} 0021140$

Kay, A. C., Whitson, J. A., Gaucher, D., and Galinsky, A. D. (2009). Compensatory control achieving order through the mind, our institutions, and the heavens. Curr. Direct. Psychol. Sci. 18, 264-268. doi: 10.1111/j.1467-8721.2009. 01649.x

Kelshaw, T., and Gastil, J. (2007). When citizens and officeholders meet (Part 1): variations in the key elements of public meetings. Int. J. Publ. Particip. 1, 1-17. Available online at: https://ssrn.com/abstract $=2735503$

Kinsella, W. J. (2004). "Public expertise: a foundation for citizen participation in energy and environmental decisions," in Communication and Public Participation in Environmental Decision Making, eds S. P. Depoe, J. W. Delicath, and M.-F. A. Elsenbeer (Albany, NY: SUNY Press), 83-98.

Kinsella, W. J., Andreas, D. C., and Endres, D. (2015). Communicating nuclear power: a programmatic review. Ann. Int. Commun. Assoc. 39, 277-309. doi: 10.1080/23808985.2015.11679178

Knobloch, K. R., Gastil, J., Reedy, J., and Cramer Walsh, K. (2013). Did They Deliberate? applying an evaluative model of democratic deliberation to the oregon citizens' initiative review. J. Appl. Commun. Res. 41, 105-125. doi: $10.1080 / 00909882.2012 .760746$

Laurin, K., Kay, A. C., and Moscovitch, D. A. (2008). On the belief in God: Towards an understanding of the emotional substrates of compensatory control. J. Experi. Soc. Psychol. 44, 1559-1562. doi: 10.1016/j.jesp.20 08.07.007

Leighninger, M. (2012). "Mapping deliberative civic engagement: Pictures from a (r)evolution," in Democracy in Motion: Evaluating the Practice and Impact of Deliberative Civic Engagement, eds T. Nabatchi, J. Gastil, M. Leighninger, and G. M. Weiksner (New York, NY: Oxford University Press), 19-39. doi: 10.1093/acprof:oso/9780199899265.003.0002

Maxwell, J., Saxena, N., Taschereau, S., and Watling, J. (2004). Responsible Action: Citizens' Dialogue on the Long-Term Management of Used Nuclear Fuel. Canadian Policy Research Networks. Retrieved from: http://www.cprn.org/doc. cfm?doc=1050andl=en

Meijers, M. H. C., and Rutjens, B. T. (2014). Affirming belief in scientific progress reduces environmentally friendly behaviour. Eur. J. Soc. Psychol. 44, 487-495. doi: $10.1002 /$ ejsp. 2009

Mirisola, A., Roccato, M., Russo, S., Spagna, G., and Vieno, A. (2014). Societal threat to safety, compensatory control, and right-wing authoritarianism: threat, compensatory control, and RWA. Polit. Psychol. 35, 795-812. doi: $10.1111 /$ pops. 12048

Mutz, D. C. (2006). Hearing the Other Side: Deliberative Versus Participatory Democracy. New York, NY: Cambridge University Press.

Nabatchi, T., Gastil, J., Weiksner, M., and Leighninger, M. (eds.). (2012). Democracy in Motion: Evaluating the Practice and Impact of Deliberative Civic Engagement. New York, NY: Oxford University Press.

Nisbet, M. C., and Myers, T. (2007). Twenty years of public opinion about global warming. Public Opin. Q. 71, 444-470. doi: 10.1093/poq/nfm031

Qiu, L., Chan, S. H. M., and Chan, D. (2018). Big data in social and psychological science: theoretical and methodological issues. J. Comput. Soc. Sci. 1, 59-66. doi: 10.1007/s42001-017-0013-6

Rechard, R. P., Cotton, T. A., and Voegele, M. D. (2014). Site selection and regulatory basis for the Yucca Mountain disposal system for spent nuclear fuel and high-level radioactive waste. Reliabil. Eng. Syst. Safety, 122, 7-31. doi: 10.1016/j.ress.2013.06.021 
Rutjens, B. T., van Harreveld, F., and van der Pligt, J. (2010). Yes we can belief in progress as compensatory control. Soc. Psychol. Person. Sci. 1, 246-252. doi: $10.1177 / 1948550610361782$

Shepherd, S., Kay, A. C., Landau, M. J., and Keefer, L. A. (2011). Evidence for the specificity of control motivations in worldview defense: distinguishing compensatory control from uncertainty management and terror management processes. J. Experi. Soc. Psychol. 47, 949-958. doi: 10.1016/j.jesp.2011.03.026

Shockley, E., and Shepherd, S. (2016). "Compensatory institutional trust: a "Dark Side" of trust," in Interdisciplinary Perspectives on Trust: Towards Theoretical and Methodological Integration, eds E. Shockley, T. M. S. Neal, L. M. PytlikZillig, and B. H. Bornstein (Cham: Springer International Publishing), 193-202. doi: 10.1007/978-3-319-22261-5_11

Sprain, L., Carcasson, M., and Merolla, A. J. (2014). Utilizing "On Tap" experts in deliberative forums: implications for design. J. Appl. Commun. Res. 42, 150-167. doi: 10.1080/00909882.2013.859292

Sprain, L., and Reinig, L. (2018). Citizens speaking as experts: expertise discourse in deliberative forums. Environ. Commun. 12, 357-369. doi: 10.1080/17524032.2017.1394894

Sullivan, D., Landau, M. J., and Rothschild, Z. (2010). An existential function of enemyship: Evidence that people attribute influence to personal and political enemies to compensate for threats to control. J. Persona. Soc. Psychol. 98, 434-449. doi: 10.1037/a0017457

Taylor, B. C., Kinsella, W. J., and Depoe, S. P. (2007). Nuclear Legacies: Communication, Controversy, and the U.S. Nuclear Weapons Complex. Lanham, MD: Lexington Books.

Trousset, S., Gupta, K., Jenkins-Smith, H., Silva, C. L., Herron, K. (2015). Degrees of engagement: using cultural worldviews to explain variations in public preferences for engagement in the policy process. Policy Stud. J. 43, 44-69. doi: $10.1111 /$ psj. 12083

Conflict of Interest Statement: The authors declare that the research was conducted in the absence of any commercial or financial relationships that could be construed as a potential conflict of interest.

Copyright $\odot 2019$ Anderson and Reedy. This is an open-access article distributed under the terms of the Creative Commons Attribution License (CC BY). The use, distribution or reproduction in other forums is permitted, provided the original author(s) and the copyright owner(s) are credited and that the original publication in this journal is cited, in accordance with accepted academic practice. No use, distribution or reproduction is permitted which does not comply with these terms. 